ISSN 1996-1944

www.mdpi.com/journal/materials

\title{
Article
}

\section{Iron Oxide Silica Derived from Sol-Gel Synthesis}

\section{Adi Darmawan ${ }^{1}$, Simon Smart ${ }^{1}$, Anne Julbe ${ }^{2}$ and João Carlos Diniz da Costa ${ }^{1, *}$}

1 FIMLab-Films and Inorganic Membrane Laboratory, School of Chemical Engineering, The University of Queensland, Brisbane Qld 4072, Australia; E-Mails: a.darmawan@uq.edu.au (A.D.); s.smart@uq.edu.au (S.S.)

2 Institut Europeen des Membranes, Universite Montpellier 2, Place Eugene Bataillon 34095, Montpellier, cedex 5, France; E-Mail: Anne.Julbe@iemm.univ-montp2.fr

* Author to whom correspondence should be addressed; E-Mail: j.dacosta@uq.edu.au; Tel.: +61-7-33656960; Fax: +61-7-33654199.

Received: 28 December 2010; in revised form: 31 January 2011 / Accepted: 16 February 2011 / Published: 17 February 2011

\begin{abstract}
In this work we investigate the effect of iron oxide embedded in silica matrices as a function of $\mathrm{Fe} / \mathrm{Si}$ molar ratio and sol $\mathrm{pH}$. To achieve homogeneous dispersion of iron oxide particles, iron nitrate nonahydrate was dissolved in hydrogen peroxide and was mixed with tetraethyl orthosilicate and ethanol in a sol-gel synthesis method. Increasing the calcination temperature led to a reduction in surface area, although the average pore radius remained almost constant at about $10 \AA$, independent of the Fe/Si molar ratio or sol $\mathrm{pH}$. Hence, the densification of the matrix was accompanied by similar reduction in pore volume. However, calcination at $700{ }^{\circ} \mathrm{C}$ resulted in samples with similar surface area though the iron oxide content increased from $5 \%$ to $50 \% \mathrm{Fe} / \mathrm{Si}$ molar ratio. As metal oxide particles have lower surface area than polymeric silica structures, these results strongly suggest that the iron oxides opposed the silica structure collapse. The effect of sol $\mathrm{pH}$ was found to be less significant than the Fe/Si molar ratio in the formation of molecular sieve structures derived from iron oxide silica.
\end{abstract}

Keywords: iron oxide; silica network; molecular sieve structures 


\section{Introduction}

The sol-gel process is a very flexible route for producing molecular sieving structures with pore radii in the region of $\sim 10 \AA$ or lower. These structures are attractive in thin film applications such as gas separation membranes and sensors. For these applications, tailoring the silica architecture is crucial, as the ideal pore size will hinder the passage of large molecules, but allow access to smaller molecules. These molecular sieving structures are often produced from the synthesis of polymeric silicate gels involving the hydrolysis of monomeric tetrafunctional alkoxide precursors and a mineral acid (e.g., $\mathrm{HCl}$ ) or a base (e.g., $\mathrm{NH}_{3}$ ), as catalysts [1]. Here, the pore size is controlled by the sol-gel synthesis conditions. Of particular importance is the water to silica molar ratio, as reasonably low $\mathrm{H}_{2} \mathrm{O} / \mathrm{Si}$ molar ratio $(<10)$ tends to inhibit the condensation reactions, thus favoring the formation of silanol groups $(\mathrm{Si}-\mathrm{OH})$ and pore sizes below $10 \AA$ [2]. Conversely, a high $\mathrm{H}_{2} \mathrm{O} / \mathrm{Si}$ molar ratio provides the sol-gel synthesis with excess water, thus benefiting the condensation reaction and the formation of siloxane bridges ( $\mathrm{Si}-\mathrm{O}-\mathrm{Si}$ ) and larger pore sizes [3].

A further important technique to tailor the pore size is to add organic templating agents during the sol-gel process [4]. In this process, organic templates trapped in the gel structure are burnt off at high temperature under oxidizing conditions, thus producing a cavity with similar dimensions to that of the template molecule [5]. Several organic templates have been employed by researchers to form microstructures [6] including methyltriethoxysilane [7], octyl-, dodecyl- or octadecyltriethoxysilane [8] and methacryloxypropyl groups [9]. Using this technique, researchers also prepared molecular sieving architectures by calcining templated sol-gels in inert atmospheres using methyltriethoxysilane [10], surfactants [11], as well as natural organic products such as sucrose [12] and starch [13].

Recently, there has been limited activity of incorporating metals and metal oxides in the sol-gel process to successfully produce molecular sieve silica. Metal oxides or metal doped silica sols were prepared through the hydrolysis and condensation of tetraethylorthosilicate (TEOS) in ethanol and hydrogen peroxide $\left(\mathrm{H}_{2} \mathrm{O}_{2}\right)$ with hydrated cobalt and nickel nitrate salts or niobia [14-18]. It is well documented in the literature that the fine control of the silica architecture and pore size tuning is possible using sol-gel processes. In this work, we investigate the effect of incorporating iron oxide into molecular sieving silica. Important parameters considered in this study are the silica to water molar ratio, iron oxide to silica molar ratio, sol $\mathrm{pH}$, functional groups, and their influence in the formation of molecular sieving structures.

\section{Results and Discussion}

Figures 1(a) and (b) display the thermogravemetric analysis (TGA) weight loss curve and the total weight loss of the iron oxide silica xerogels, respectively. The total weight loss was almost unaltered when the Fe/Si molar ratio increased from 0 to $3.125 \%$, however there is a marked decrease in weight loss at $\mathrm{Fe} / \mathrm{Si} 6.25 \%$ corresponding to the minimum weight loss observed for all samples. From there on, the total weight loss increased exponentially each time that the Fe/Si molar ratio increased. These results strongly suggest that the addition of iron affects the sol-gel processes. These trends can also be observed as each curve evolves through the heat treatment in air as shown in Figure 1(a). For instance, the blank and $3.125 \%$ samples show similar TGA curves, while the remaining samples from $6.25 \%$ to $50 \%$ show similar trends to each other but different to the blank sample. In terms of TGA behavior, the 
$3.125 \%$ iron content sample is behaving like the blank silica sample, so the small addition of iron is not significant. On the other hand, for samples $6.25 \%$ and above, it appears the iron content plays a major role. This is increasingly evident as the individual weight loss peaks are analyzed across the samples. From $80-120^{\circ} \mathrm{C}$, the weight loss is generally caused by the loss of free (not chemically bound) $\mathrm{H}_{2} \mathrm{O}$ and ethanol molecules, and there is a sharp increase in weight loss that is again associated with the increase of $\mathrm{Fe} / \mathrm{Si}$ molar ratio, suggesting that an increasing iron content results in increased $\mathrm{H}_{2} \mathrm{O}$ within the uncalcined xerogel matrix.

Figure 1. (a-left) Mass (\%) curves (calculated relative to mass at room temperature); (b-right) total weight loss. Both are as a function of the Fe/Si molar ratio.
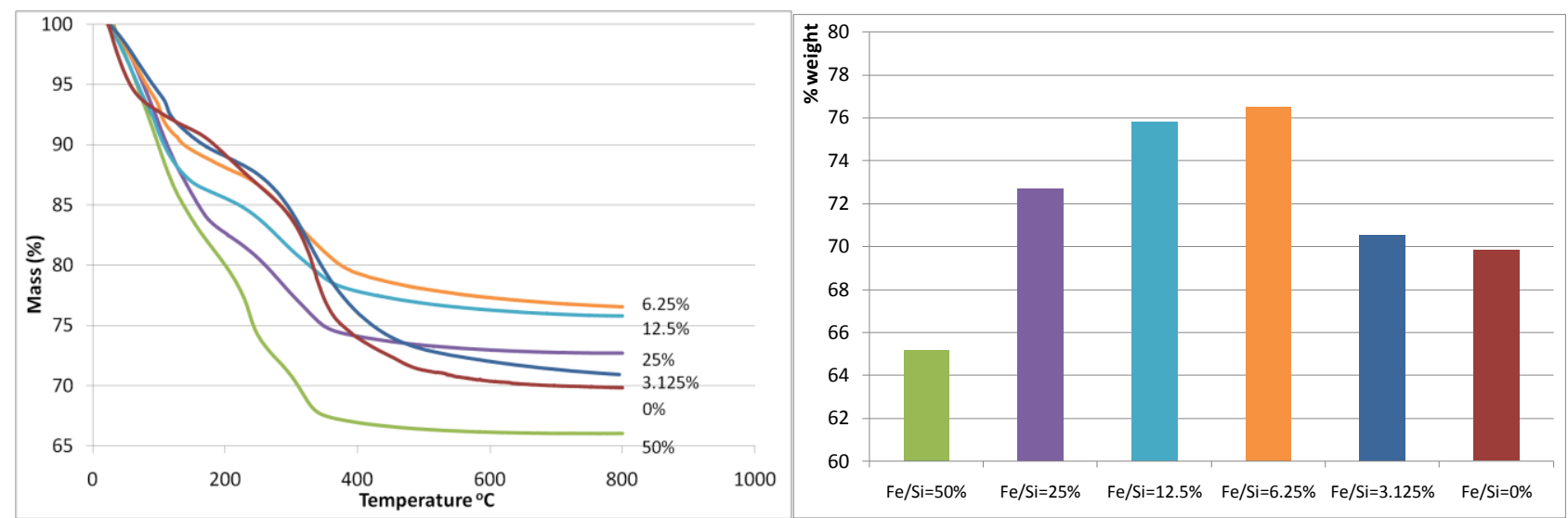

Figure 2. Differential of the TGA for samples prepared with varying Fe/Si molar ratios.

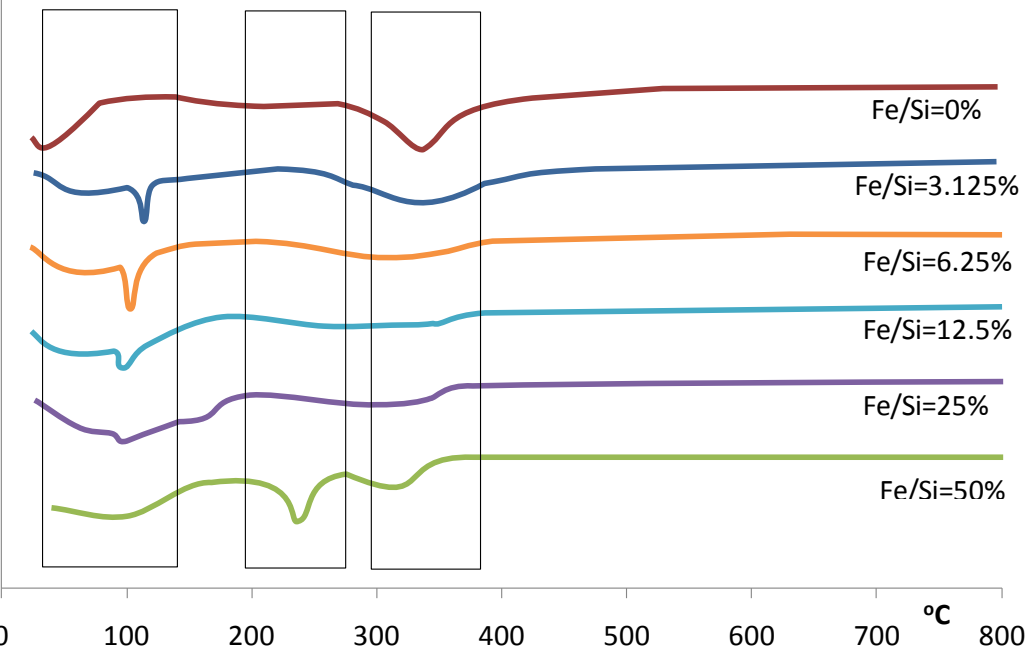

This trend continues over the next weight loss peaks between $120-400{ }^{\circ} \mathrm{C}$, whereby increasing weight losses coincide with increasing iron content. This is especially true for the $50 \% \mathrm{Fe} / \mathrm{Si}$ molar ratio sample. For pure silica sol-gels analyzed by TGA within this temperature range, the weight losses are generally associated with the condensation reactions due to heat treatment, resulting in the production of water and ethanol, which evaporates from the silica matrix. However, the decomposition of iron nitrate nonahydrate should lead to the formation of a coordinated $\mathrm{Fe}(\mathrm{OH})_{6}$ octahedral 
structure [19], where $\mathrm{Fe}$ is surrounded by six oxygen atoms corresponding to $\mathrm{OH}$ groups or $\mathrm{H}_{2} \mathrm{O}$ molecules. Due to the fact that a reasonable amount of water agglomerates around iron, increasing the iron content in the sol-gel will likewise significantly increase the amount of water in the sample. The additional weight loss seen for increasing iron content is therefore assigned to the removal of additional water, as well as solvents (ethanol) and organics (R groups from TEOS). Furthermore, the nitrate decomposition, related to the removal of $\mathrm{HNO}_{3}$ from the hydrated salt [19] and eventual $\mathrm{NO}$ and $\mathrm{NO}_{2}$ formation which may take place around $230-240{ }^{\circ} \mathrm{C}$, must also be considered. This decomposition is observed in the dTGA differential analysis in Figure 2 for the $50 \% \mathrm{Fe} / \mathrm{Si}$ molar ratio sample.

Figures 3(a) and 3(b) show the IR spectra of xerogel samples between wave number 1300 and $580 \mathrm{~cm}^{-1}$. It is observed that regardless of the $\mathrm{Fe} / \mathrm{Si}$ molar ratio variation, or $\mathrm{pH}$ variation, the IR spectra of the xerogel samples remained almost constant. These results suggest that no significant variation of silica functional groups was attained by introduction of iron and $\mathrm{pH}$ changes. These results concur with previous literature in the sense that the $\mathrm{H}_{2} \mathrm{O} / \mathrm{Si}$ molar ratio was kept constant in the sol for all samples [3]. Hence, the formation of the silanol and siloxane groups was still governed by the silica hydrolysis and condensation reactions.

Figure 3. IR spectra of iron oxide silica xerogel samples as a function of (a-left) $\mathrm{Fe} / \mathrm{Si}$ molar ratio; (b-middle) $\mathrm{pH}$ for $10 \% \mathrm{Fe} / \mathrm{Si}$ molar ratio sample; and (c-right) calcinations temperature for $10 \% \mathrm{Fe} / \mathrm{Si}$ molar ratio sample.
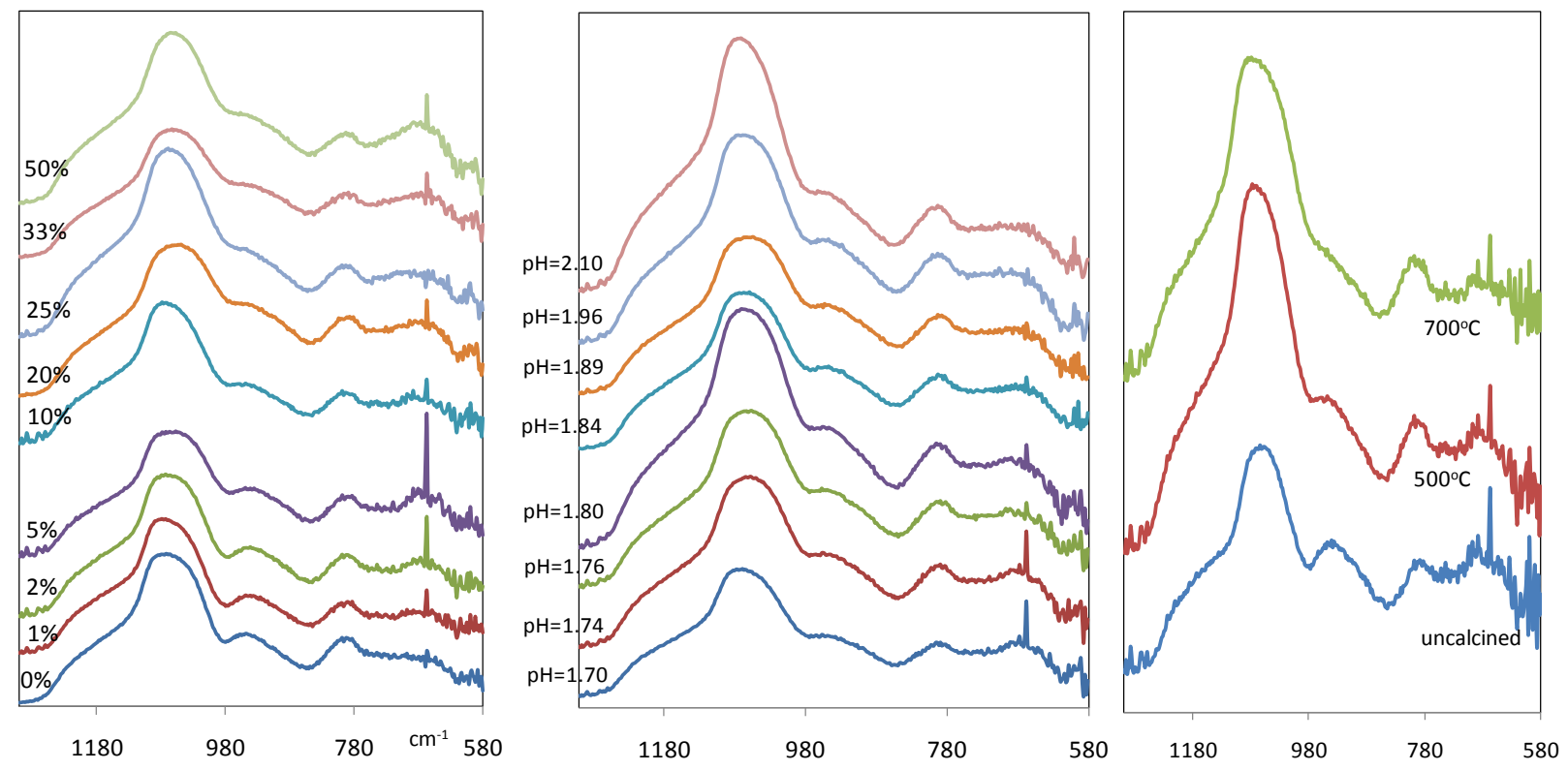

However, a notable difference in Figures $3 \mathrm{a}$ and $3 \mathrm{~b}$ is a new band which is observed at $667 \mathrm{~cm}^{-1}$. This band becomes more prominent as the Fe/Si molar ratio increases towards 50\%, and it was not found in the pure silica xerogel. Since there are no corresponding bands in the infrared spectra of silica in this region, this new band is most probably associated with Fe-O stretching vibration, a region generally associated with metal oxides [17]. The other bands observed are conventionally found in silica materials as reported elsewhere [20-22]. This includes the bands at $800 \mathrm{~cm}^{-1}$ and $1076 \mathrm{~cm}^{-1}$ with a shoulder near $1200 \mathrm{~cm}^{-1}$ corresponding to different modes of siloxane stretching bonds (Si-O-Si): 
symmetric and asymmetric, respectively. The shoulder in the region of $960 \mathrm{~cm}^{-1}$ is assigned to the stretching vibration of $\mathrm{Si}-\mathrm{OH}$.

Figure 3(c) compares the IR spectra of iron oxide silica xerogel samples before and after calcination at 500 and $700{ }^{\circ} \mathrm{C}$. The band at $\sim 960 \mathrm{~cm}^{-1}$ associated with silanol groups, is weakened gradually with heat treatment, changing from a distinct peak for the uncalcined sample to a broad shoulder at $500{ }^{\circ} \mathrm{C}$. In addition, the intensity of the peak around $1080 \mathrm{~cm}^{-1}$, assigned to siloxane bridges, increased. These changes are attributed to condensation reactions, and supports the view that polycondesation allows for the transformation of silanols to siloxane bridges. As heat treatment progresses, the band at $1067 \mathrm{~cm}^{-1}$ for the uncalcined sample shifts to 1076 and $1083 \mathrm{~cm}^{-1}$ at 500 and $700{ }^{\circ} \mathrm{C}$, respectively. This is interpreted as changes in the xerogel network caused by irreversible shrinkage in the silica polymeric bonding derived from heat treatment. In addition, it is observed that there are no bands assigned to Fe-O-Si bonds at $\sim 490 \mathrm{~cm}^{-1}$ region as reported elsewhere [23-24]. These results clearly suggest that calcination results in the formation of a mixed matrix of polymeric silica and iron oxide particles.

Figure 4 shows typical nitrogen adsorption isotherms of iron oxide silica xerogels calcined at $500{ }^{\circ} \mathrm{C}$. These isotherms are type 1 , characteristic of microporous materials. These results suggest that that sol-gel method used in this work essentially produced molecular sieves of similar structure, independently of the content of iron oxide added to the silica matrix. The average pore radius remained similar for all samples at around $10 \AA( \pm 0.5 \AA)$ though pore volumes and surface areas varied depending upon the preceding sol-gel synthesis conditions and calcination temperatures. The only exception was the sample synthesized with $\mathrm{pH} 2.1$, close to the precipitation point of the sol-gel, which showed an average pore radius of $11.7 \AA( \pm 0.5 \AA)$.

Figure 4. Nitrogen sorption isotherms of samples with varying $\mathrm{Fe} / \mathrm{Si}$ molar ratio for sample calcined $500{ }^{\circ} \mathrm{C}$.

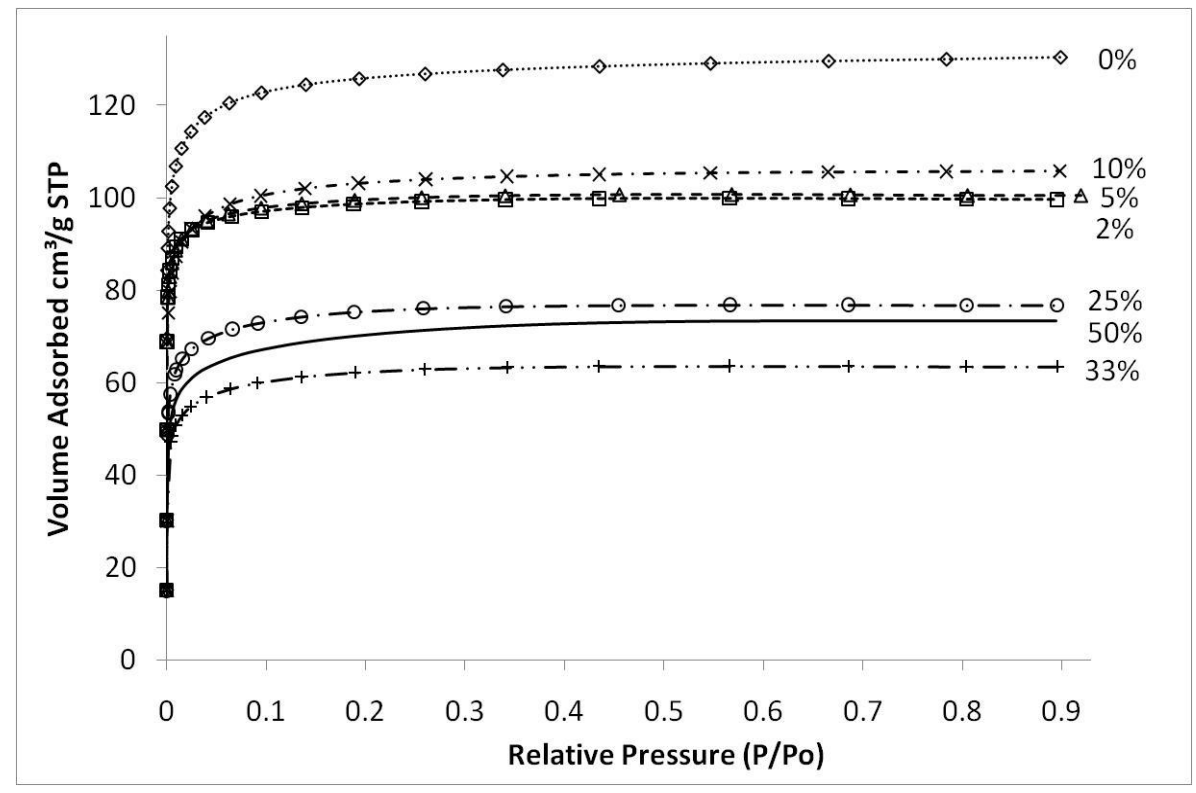

Figure 5a shows the resultant BET (Brunauer, Emmett and Teller) surface area as a function of $\mathrm{Fe} / \mathrm{Si}$ molar ratio. First of all, the effect of temperature calcination is consistent with conventional pure 
silica calcination. That is that increasing the calcination temperature densifies the silica matrix. The initial changes from the blank sample to $2 \% \mathrm{Fe} / \mathrm{Si}$ molar ratio resulted in a significant reduction in surface area of $33 \%$ and $~ 50 \%$ at 500 and $700{ }^{\circ} \mathrm{C}$, respectively. From there on, surface areas tended to increase and then slightly decrease as the iron oxide content increases. Similar trends were also observed for changes of pore volume versus $\mathrm{Fe} / \mathrm{Si}$ molar ratio, as the average pore radius remained constant around $10 \AA( \pm 0.5 \AA)$. The initial subtle changes for the $2 \% \mathrm{Fe} / \mathrm{Si}$ sample seems to be an anomaly, though it could be correlated to the TGA trends displayed in Figure 1. At low Fe/Si ratio, the iron oxide effect is not significant, and in this case does not oppose the densification of the silica matrix. Similar to the TGA results, increasing the iron oxide content further provides beneficial structural stability. This point is clearly observed in Figure 5b. In principle the surface area and microporous pore volume should reduce as the amount of iron oxide particles, which generally have a low surface area as compared to polymeric silica, increases and the silica content decreases per gram of sample. This is not the case, thus suggesting that iron oxide particles were homogeneously dispersed in the silica matrix. In addition, the iron oxides opposed a greater collapse of the silica matrix, particularly as the Fe content increased from 33 to 50\%, as the surface areas per mole of silica increased.

Figure 5. (a-left) Surface area of samples; and (b-right) surface area per mole of silica, as a function of $\mathrm{Fe} / \mathrm{Si}$ molar ratio.
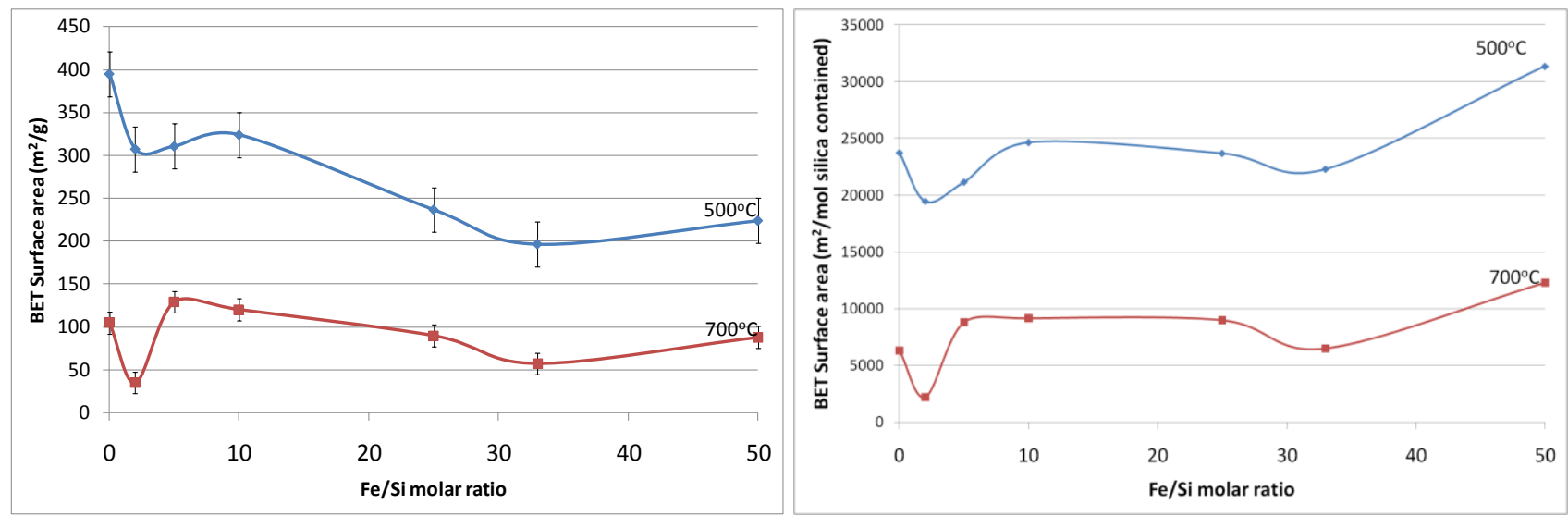

Figure 6 displays the surface area as a function of the $\mathrm{pH}$, which was modified by adding an aqueous ammonia solution. Again, increasing the calcination temperature from 500 to $700{ }^{\circ} \mathrm{C}$ led to the densification of the iron oxide silica matrix. The surface area did not change significantly as the $\mathrm{pH}$ increased from 1.7 to 1.825 , while slightly reducing the surface area from thereon. For $\mathrm{pH}$ values above 2.10, the sol-gel agglomerated and precipitated, and was no longer considered in this work as it was no longer in polymeric form. 
Figure 6. Surface area of samples as a function of $\mathrm{pH}$.

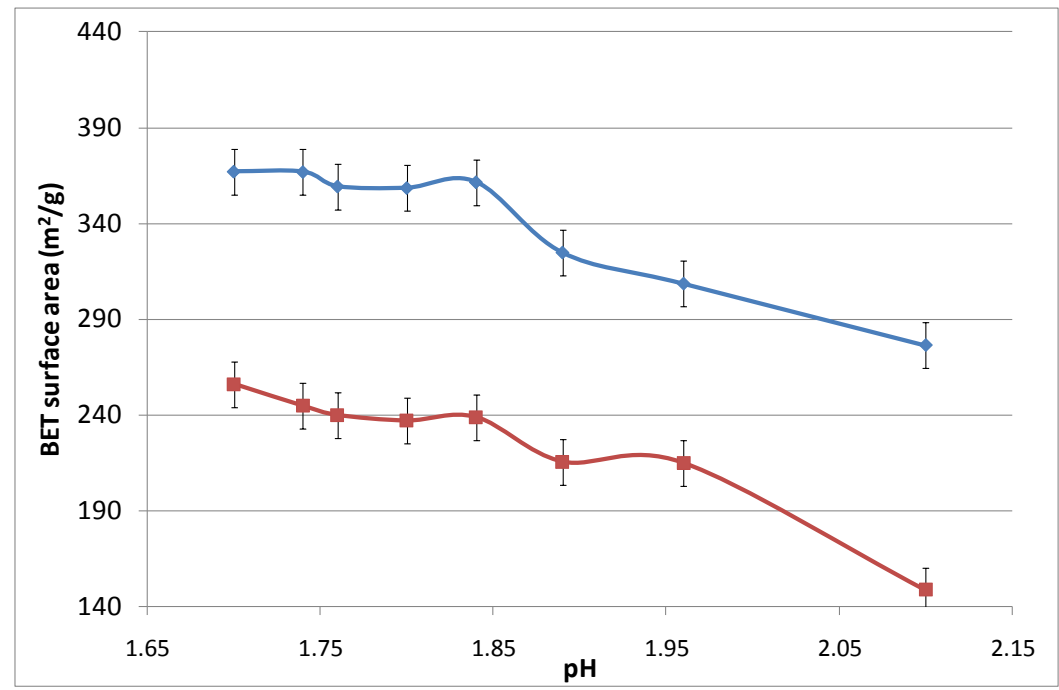

\section{Experimental Section}

The iron oxide silica sol was prepared similar to metal oxide silica sol methods described elsewhere [17], the major difference being the use of iron oxides instead of nickel or cobalt oxides. Briefly, iron oxide sols were synthesized by the hydrolysis and condensation of tetraethyl orthosilicate (TEOS) in ethanol and $30 \%$ aqueous $\mathrm{H}_{2} \mathrm{O}_{2}$ with iron nitrate nonahydrate $\left(\mathrm{Fe}\left(\mathrm{NO}_{3}\right)_{3} \cdot 9 \mathrm{H}_{2} \mathrm{O}\right)$. An initial molar ratio of $255 \mathrm{EtOH}: 4$ TEOS: $\mathrm{Fe}\left(\mathrm{NO}_{3}\right)_{3} \cdot 9 \mathrm{H}_{2} \mathrm{O}: 9 \mathrm{H}_{2} \mathrm{O}_{2}: 40 \mathrm{H}_{2} \mathrm{O}$ was mixed and vigorously stirred for 3 hours in an ice-cooled bath. The number of moles of iron nitrate nonahydrate, $\mathrm{x}$, was varied between $0-2$ and the $\mathrm{pH}$ was adjusted with aqueous ammonia to determine the synthesis effects on the silica structure. The molar ratio is defined as the number of moles of Fe species divided by the number of moles of Si species. It should be noted that the water of crystallization was taken into account when calculating the water to silica molar ratio. A blank silica sample $(\mathrm{x}=0)$ having no iron oxide was also prepared for comparison with the iron oxide silica.

Sol samples were dried in a temperature-controlled oven at $60{ }^{\circ} \mathrm{C}$ at atmospheric conditions to form a xerogel. The xerogel samples were crushed finely and calcined at ramp rates $1.5{ }^{\circ} \mathrm{C} \min ^{-1}$ to $500{ }^{\circ} \mathrm{C}$ and $700{ }^{\circ} \mathrm{C}$ in an oxidizing (air) atmosphere with a 3 hour holding time at the desired temperature. Nitrogen adsorption was studied at $77 \mathrm{~K}$ using a Micromeritics Tristar 3000 to determine the BET surface area. The samples were initially degassed for $24 \mathrm{~h}$ to pressures of $\sim 2 \mathrm{~Pa}$ at $200{ }^{\circ} \mathrm{C}$. Fourier transform infrared analysis (FTIR) was carried out on a Shimadzu IRAffinity-1 with a Pike MIRacle ATR attachment. Spectra were taken over a wavelength range of $1300-580 \mathrm{~cm}^{-1}$. Thermogravetric analysis (TGA) was performed using a Shimadzu TGA-50. Xerogel powders were heated at $2.0{ }^{\circ} \mathrm{C} \mathrm{min}^{-1}$ up to $800{ }^{\circ} \mathrm{C}$ with an air flow rate of $80 \mathrm{~mL} \mathrm{~min}^{-1}$.

\section{Conclusions}

The findings of this work clearly indicate that the content of iron oxide in the silica matrix has a significant effect on the resultant material matrix. Large weight losses were associated with $\mathrm{OH}$ groups or $\mathrm{H}_{2} \mathrm{O}$ molecules derived from the decomposition of iron nitrate nonahydrate in addition to solvents (ethanol) and organics (R groups from TEOS). Furthermore, nitrate decomposition under heat 
treatment led to $\mathrm{NO}$ and $\mathrm{NO}_{2}$ formation, further contributing to weight losses. In other words, increasing the $\mathrm{Fe} / \mathrm{Si}$ molar ratio similarly increases the weight losses. No observable changes in the silica functional groups were found, thus suggesting no significant variation of silica functional group formation as a function of iron oxide content or sol $\mathrm{pH}$.

The average pore radius remained almost constant in the region of $10 \AA$, indicating that surface areas and pore volumes varied proportionally with the calcination temperature, though resulting in the densification of the material matrix. However, calcination at $700{ }^{\circ} \mathrm{C}$ resulted in samples with similar surface area as the iron oxide content increased from $5 \%$ to $50 \% \mathrm{Fe} / \mathrm{Si}$ molar ratio. This result is counterintuitive as the increase in iron oxide content should decrease the total surface area. As metal oxide particles have low surface area than polymeric silica structures, these results strongly suggest that the iron oxides played a beneficial role in opposing the silica structure collapse.

\section{Acknowledgements}

Adi Darmawan acknowledges scholarship support from the University of Queensland. The authors acknowledge financial support from the Australian Research Council (DP110101185).

\section{References}

1. Brinker, C.J.; Scherer, G.W. Sol Gel Science: The Physics and Chemistry of the Sol Gel Processing; Academic Press: San Diego, CA, USA, 1990.

2. Diniz da Costa, J.C.; Lu, G.Q.; Rudolph, V.; Lin, Y.S. Novel molecular sieve silica (MSS) membranes: Characterisation and permeation of single-step and two-step sol-gel membranes. J. Memb. Sci. 2002, 198, 9-21.

3. Brinker, C.J.; Hurd, A.J.; Ward, K.J. Fundamentals of sol-gel thin-film formation. In Ultrastructure Processing of Advanced Ceramics; Mackenzie, J.D., Ulrich, D.R., Eds.; Wiley: New York, NY, USA, 1988; pp. 223-253.

4. Raman, N.K.; Anderson, M.T.; Brinker, C.J. Template-based approaches to the preparation of amorphous nanoporous silicas. Chem. Mater. 1996, 8, 1682-1701.

5. Beck, J.S.; Vartuli, J.C.; Kennedy, G.J.; Kresge, C.T.; Roth W.J.; Schramm S.E. Molecular or supramolecular templating: Defining the role of surfactant chemistry in the formation of microporous and mesoporous molecular sieves. Chem. Mater 1994, 6, 1816-1821.

6. Julbe, A.; Balzer, C.; Barthez, J.M.; Larbot, A.; Guizard, C.; Cot, L. Effect of non-ionic surface active agents on TEOS derived sols, gels and materials. J. Sol-gel Sci. Tech. 1995, 4, 89-97.

7. Raman, N.K.; Brinker, C.J. Organic template approach to molecular sieving silica membranes. J. Memb. Sci. 1995, 105, 273-279.

8. Kusakabe, K.; Sakamoto, S.; Saie, T.; Morooka, S. Pore structure of silica membranes formed by a sol-gel technique using tetraethoxysilane and alkyltriethoxysilanes. Sep. Pur. Tech. 1999, 16, 139-146.

9. Lu, Y.; Cao, G.; Kale, R.P.; Prabakar, S.; Lopez, G.P.; Brinker; C.J. Microporous silica prepared by organic templating: relationship between the molecular template and pore structure. Chem. Mater. 1999, 11, 1223-1229 
10. De Vos, R.M., Maier, W.F.; Verweij, H. Hydrophobic silica membranes for gas separation. J. Memb. Sci. 1999, 158, 277-288.

11. Duke, M.C.; Diniz da Costa, J.C.; Do, D.D.; Lu, G.Q.; Gray, P.G.; Thompsett, D. Hydrophilic hydrostable functionalised silica surfaces. Adv. Func. Mater. 2006, 16, 1215-1220.

12. Diniz da Costa, J.C.; Coombs, S.; Lim, J.; Lu, G.Q. Characterisation of xerogels derived from sucrose templated sol-gel synthesis. J. Sol-Gel Sci. Tech. 2004, 31, 215-218.

13. Coombs, S.; Diniz da Costa, J.C. Characterisation of sol-gel processes employing starch as organic templates. Mater. Forum 2005, 29, 143-146.

14. Kanezashi, M.; Asaeda, M. Hydrogen permeation characteristics and stability of Ni-doped silica membranes in steam at high temperature. J. Memb. Sci. 2006, 271, 86-93.

15. Igi, R.; Yoshioka, T.; Ikuhara, Y.H.; Iwamoto, Y.; Tsuru, T. Characterization of co-doped silica for improved hydrothermal stability and application to hydrogen separation membranes at high temperatures. J. Am. Ceram. Soc. 2008, 91, 2975-2981.

16. Boffa, V.; Blank, D.H.A.; ten Elshof, J.E. Hydrothermal stability of microporous silica and niobia-silica membranes. J. Memb. Sci. 2008, 319, 256-263

17. Uhlmann, D.; Liu, S.; Ladewig, B.P.; Diniz da Costa, J.C. Cobalt-doped Silica membranes for gas separation. J. Memb. Sci. 2009, 326, 316-321.

18. Battersby, S.; Ladewig, B.; Liu, S.; Duke, M.C.; Rudolph, V.; Diniz da Costa, J.C. Hydrothermal stability of cobalt doped silica membranes in a water gas shift membrane reactor. Sep. Pur. Tech. 2009, 66, 299-305.

19. Wieczorek-Ciurowa, K.; Kozak, A.J. The thermal decomposition of $\mathrm{Fe}\left(\mathrm{NO}_{3}\right)_{3} 9 \mathrm{H}_{2} \mathrm{O}$. J. Thermal Analys. Calorim. 1999, 58, 647-651.

20. Bertolluzza, A.; Gagnano, C.; Morelli, M.A.; Gottardi V.; Guglielmi M. Raman and Infrared spectra of silica gel evolving toward glass. J. Non-Cryst. Solids 1982, 48, 117-128.

21. Duran, A.; Serna, C.; Fornes, V.; Fernadez Navarro, J.M. Structural considerations about $\mathrm{SiO}_{2}$ glasses prepared by sol-gel. J. Non-Cryst. Solids 1986, 82, 69-77.

22. Burneau, A.; Gallas J.P. Vibrational spectroscopy. In The Surface Properties of Silicas; Legrand, A.P., Ed.; John Wiley \& Sons: Chichester, UK, 1988; pp. 147-234.

23. Komadel, P.; Madejova, J.; Stuck, J.W. Reduction and reoxidation of nontronite: Questions of reversibility. Clays Clay Miner. 1995, 43, 105-110.

24. Russell, J.D.; Fraser, A.R. Clay Mineralogy: Spectroscopic and Chemical Determinative Methods; Wilson, M.J., Ed.; Chapman and Hall: London, UK, 1994; p. 11.

(C) 2011 by the authors; licensee MDPI, Basel, Switzerland. This article is an open access article distributed under the terms and conditions of the Creative Commons Attribution license (http://creativecommons.org/licenses/by/3.0/). 